\title{
Students' Perceptions on Practical Problem Solving in Mathematics in E-environment
}

\author{
http://dx.doi.org/10.3991/ijep.v4i2.3446 \\ A.Zeidmane, V. Duka \\ Latvia University of Agriculture (LUA), Jelgava, Latvia
}

\begin{abstract}
Study process in mathematics faces two major problems. First, engineers do not apply directly the problem solving skills of higher mathematics. Second, studying higher mathematics, students get an insufficient idea of its usability. The authors of the paper have worked out frameworks for practical problem solving in mathematics on the basis of didactic ontology in the Moodle computerized learning system (CMS. To determine students' perceptions on practical problem solving in mathematics in e-environment, more than 300 students from the specialties of engineering at the LUA participated in the survey. The survey results showed many students lack basic knowledge in mathematics, therefore they consume a lot of time to learn the basics in higher mathematics and to acquire the skills of practical problem solving in mathematics are less important.
\end{abstract}

Index Terms-usability of mathematics, e-learning environment students' perception.

\section{INTRODUCTION}

European higher education reformation known as the Bologna Process has come to a close, its impact on the field of mathematics is significant in many ways. Mathematical competence is an imprescriptibly part of any engineering education. Almost all branches of engineering rely on mathematics as the language of description and analysis. Mathematical competences have a complicated structure. One of widely used concepts of mathematical competence was developed in Denmark and later adopted in the famous OECD PISA study [1]. M. Niss [2] stated, "Possessing mathematical competence means having knowledge of, understanding, doing and using mathematics and having a well-founded opinion about it, in a variety of situations and contexts where mathematics plays or can play a role." The issue of mathematical competence has become one of the key education priorities at EU policy level. According Eurydice [3], "in the past years, and especially since 2007, the great majority of European countries have revised their mathematics curricula, adopting an outcome-based approach whereby the focus lies on developing students' competences and skills rather than on theoretical content".

Mathematics degrees and programs are changing across Europe, and in some cases, with serious side effects. On the other hand, there have been considerable increases in the percentage of international students, who tend to major in mathematics and mathematics-related fields, attending European universities [4]. European Society for Engineering Education (SEFI) in the latest edition of "Framework for Mathematics Curricula in Engineering Education" [5] states that although contents are still important, however, to develop skills to use and apply mathematical concepts in relevant contexts and situations certainly are a predominant goal of the mathematical education for engineers in the 21 st century.

The ERDF project "Cross-border network for adapting mathematical competences in the socio-economic development (MatNet)" [6] has been implemented since 2011 by the Departments of Mathematics of the Latvia University of Agriculture and Siauliai University in Lithuania to research the development opportunities of mathematical competences and preparing recommendations for improvements of mathematics study programs. The first year of the project was devoted to the internal and external research. The external research included the analysis of regional strategic plans and other national documents and the questionnaire was designed and uploaded in the project website "Mathematics in professional activities" in the English, Latvian and Lithuanian languages.

During internal research the interviews were carried out with the programme directors, academic personnel and social partners. The majority of them recognize the role of mathematics in the development of logical thinking, but, unfortunately, study programmes have ECTS restrictions and directors of study programmes are interested to give more ECTS to special subjects and less ECTS to general subjects, including mathematics. Unfortunately, the survey showed that the majority of lecturers hardly ever apply higher mathematics in the special subjects. The "ready-made" formulas are analyzed and respective processes described. Meanwhile, lecturers are disappointed with students' basic knowledge in mathematics which is mostly necessary to perform calculations.

Analyzing the results of external and internal research two major issues were identified:

1. studying higher mathematics, students get an insufficient idea of its usability,

2. engineers do not apply directly the problem solving skills of higher mathematics;

It is necessary to identify the required knowledge and skills for solving practical problems in mathematics, gaps of the study process to include more practical problem solving in mathematics study process, and find the way how to integrate mathematics usability in the study process.

With regards to mathematics application the problems are:

1. mathematics study course is included in the 1 st and 2nd year of the programme when the students have insufficient knowledge in their special subjects;

2. mathematics teacher as a nonprofessional should explain technical concepts which are taken out of con- 
text and therefore they are not well understood by students;

3. the number of ECTS in mathematics is reduced and there is no time to solve practical mathematical tasks.

\section{MEthods}

\section{A. Organization of self-directed study using e-learning features}

One of the solutions of the problem could be the application of e-environment, but it is connected with students' self-directed study.

Role of students in the e-learning is very significant. "Fig.1".

E-learning is learning (self-education, study) through electronic teaching tool, books, textbooks, that can be distributed in various ways and students can obtain study materials and information also by means of new information and communication technologies. At the same time, it is based on voluntary approach, consciousness, responsibility and ambitions of an individual student who is self-responsible for the selection of his study materials, the way he studies, his specialization as well as the search for possibilities of obtaining a certificate for his knowledge. They themselves state (programmes) the goals of their education and adapts them to their own needs, conditions, life rhythm and lifestyle.

To achieve this goal, the LUA chose Moodle computerized learning system (CMS), which is one of the largest elearning systems [7]. At the LUA this system is used as elearning tool since September, 2010. Moodle has two main tools for problem solution mentioned before - glossary auto-linking filter and lesson module "Fig.2".

The Glossary activity is one of the Moodle features which can store the list of definitions for specific terms, it is like vocabulary. Glossary auto-linking filter is creating links to glossary activity entry where the word or phrase of the glossary entry is used within the same course in which glossary is located [8]. When this setting is turned on, whenever a word from a Glossary appears in the course, it is highlighted in gray.

Clicking on the word brings up a pop-up window containing the word's Glossary entry. The lesson module presents a series of HTML pages to the student who is usually asked to make some sort of choice underneath the content area [9]. The choice will send them to a specific page in the Lesson. In a Lesson page's simplest form, the student can select a continue button at the bottom of the page, which will send them to the next page in the Lesson.

For understanding practical application of mathematics it is necessary to have additional knowledge in specific terms and regularities. Mathematics teacher in cooperation with the special subject teacher create glossary autolinking filter, which contains those terms and laws that will be taught in later on in the respective special subjects.

\section{B. Didactical approach of e-learning}

It is very important to find the way how to organize the self-directed study of mathematics' practical application based on didactic approach and e-learning features. Learning process consists of several didactical objects. It is necessary to recognize each object's role and hierarchy in the learning process. On the basis of Mencke S. and Dumke R.R. research [10], the authors applied didactic object

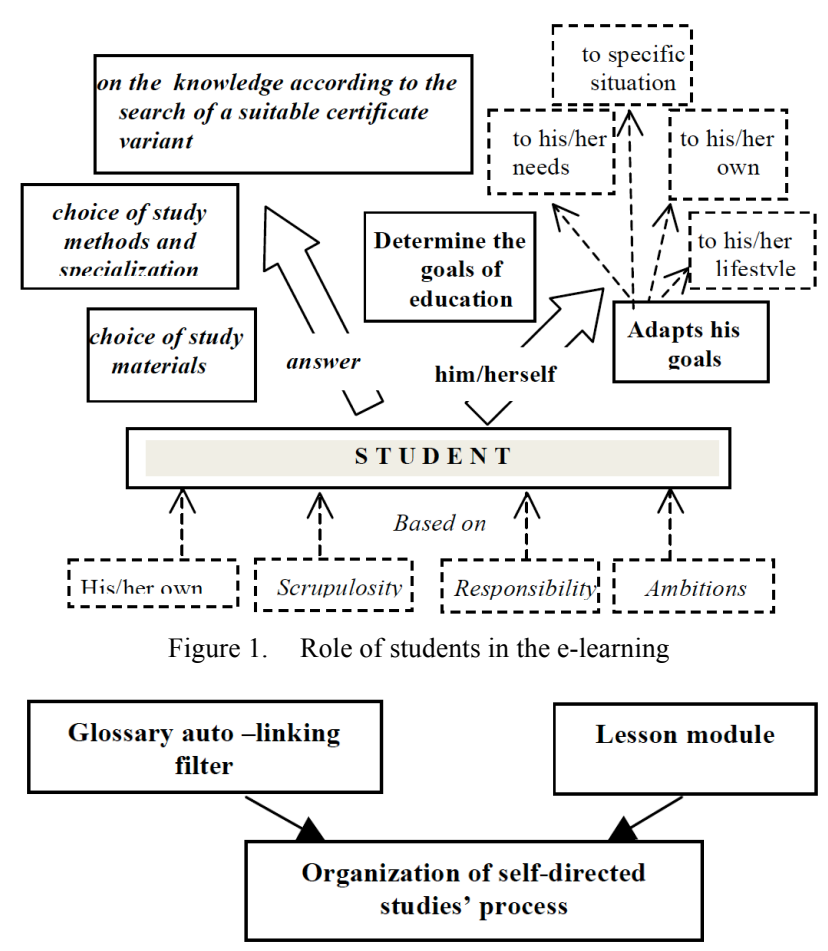

Figure 2. Moodle tools for organization of self-directed studies' process

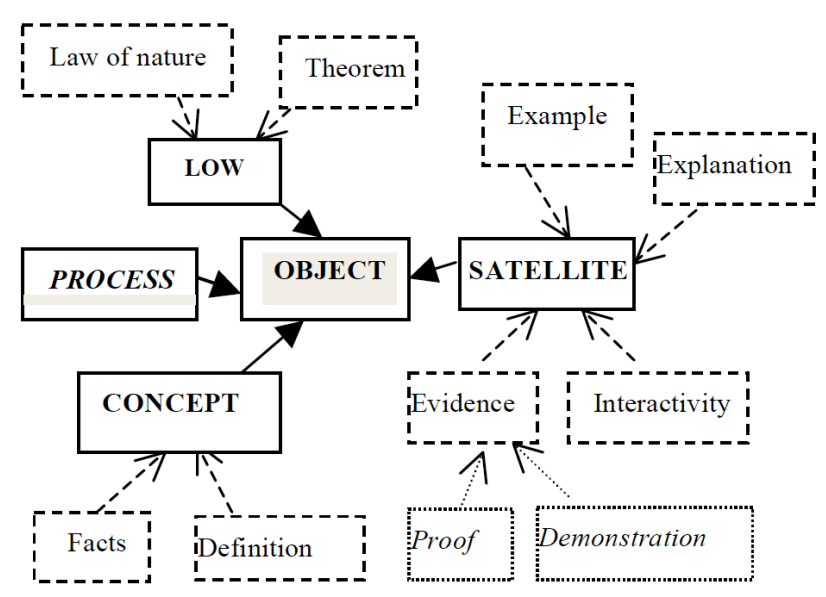

Figure 3. Hierarchy of Didactical Objects

classification for organization of Practical Problem Solving in Mathematics in E-environment "Fig.3".

The concepts and laws are necessary for learning, satellites are used for understanding. Concepts consist of facts and definitions, laws consist of laws of nature and theorems. The required components of the satellite are an example, explanation, evidence and interactivity. In order to increase awareness, it is important to give examples of different types, such as comprehension examples, evaluation examples, knowledge example, analysis examples, synthesis examples etc. Explanation consists of an introduction, conclusion and some remarks. A demonstration is used for visual evidence, a proof is used for theoretical evidence. E-learning environment offers a variety of interactivities, which may include various types of exercises, such as comprehension exercises, evaluation exercises, knowledge exercises, analysis and synthesis exercises, application exercises etc., as well as real world problem and exploration. 


\section{Practical problem solving in mathematics in e- environment}

Practical problem solving in mathematics in eenvironment is based on hierarchy of didactical objects, but for organization of self-directed studies it is necessary to design frameworks which consist of problem solving steps. Using mathematics we can solve general problems which comprise general tasks and practical problems which consist of a task with known and unknown values „Fig.4.”.

For example, for solution of general problem "Draw up the differential equation of damped harmonic motion and find a solution", firstly, we should make judgments (step 1 in Fig.4.), which in this case mean: 1.1. Find the general regularities which describe the given phenomenon (motion); 1.2. Find the values that characterize a specific phenomenon (damped harmonic motion); 1.3. Insert the values that characterize a specific phenomenon (damped harmonic motion) into the general law (Newton's second law); 1.4. Insert the Hooke's law and Stokes' law into Newton's second law; 1.5. Write the equation using the differential forms of velocity and acceleration. If he/she has a problem to solve this step, he/she can get answer for each step separately. The second step is to make mathematical improvements and find the physical essence of constants (step 2 in Fig.4), which means in a concrete problem: 2.1. Transform equation using the derivative symbols; 2.2. Divide with $\mathrm{m} ; 2.3$. Denote coefficients before $x^{\prime}$ and $x ; 2.4$. Write the differential equation of damped harmonic motion. The third step mathematical calculation (step 3 in Fig.4) what in concrete problem means: 3.1. Write the auxiliary equation; 3.2. Calculate the roots $\lambda_{1,2} ; 3.3$. Solve the equation, if the damping is big; 3.4. Solve the equation, if the damping is low. The last step provides the answer.

Different steps are necessary for solutions of practical problems "Fig.5".

Firstly, the problem must be formulated using the picture, terms and symbols, and known and unknown values must be separated (step 1 in Fig.5.). After problem formulation students have to express regularities for unknown values, respectively, the help with an included answer can be received. In this step just general regularities are expressed, but problem specific regularities must be judged by students independently, again if there is some problem for solving these, extra answers can be received (steps 2 3 in Fig.5.). Then it is necessary to find out relationship between obtained and given known value, extra regularities are given (answer in step 4) for extra support. When regularities are obtained, it is necessary to choose the correct solution method; in any case, students have access to the answer in step 5, where correct mathematical method is given. Then a mathematical calculation follows which will give problem solution for students, mathematical calculation is supported with suggestions and mathematical methods (step 6 in Fig.5.). The last step is the answer.

As mentioned in problem solving step by step, students have an opportunity to view the answer that contains a lot of concepts and laws relating to both the theme and the mathematics. Therefore, to establish a correct concept and law dictionary, mathematics teachers need to cooperate with the special subject teachers.

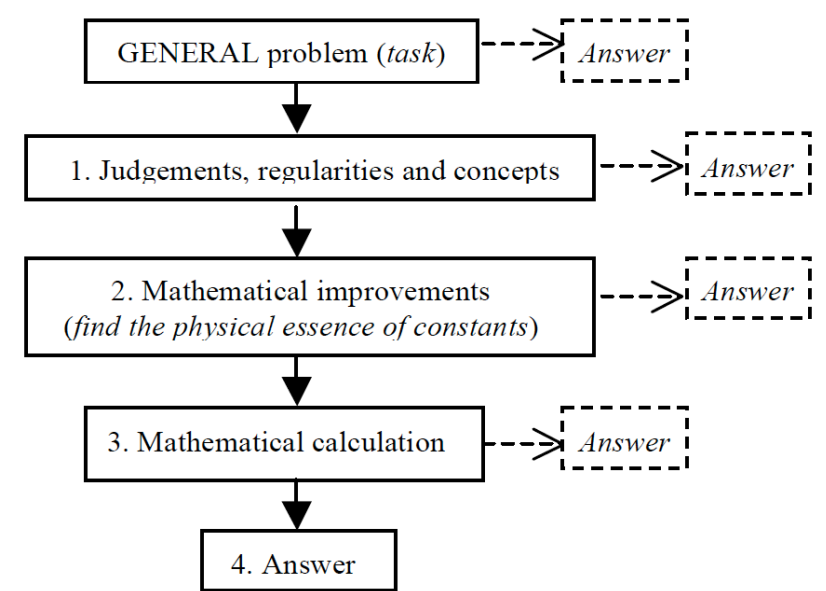

Figure 4. Frameworks for organization of general problem solving in mathematics

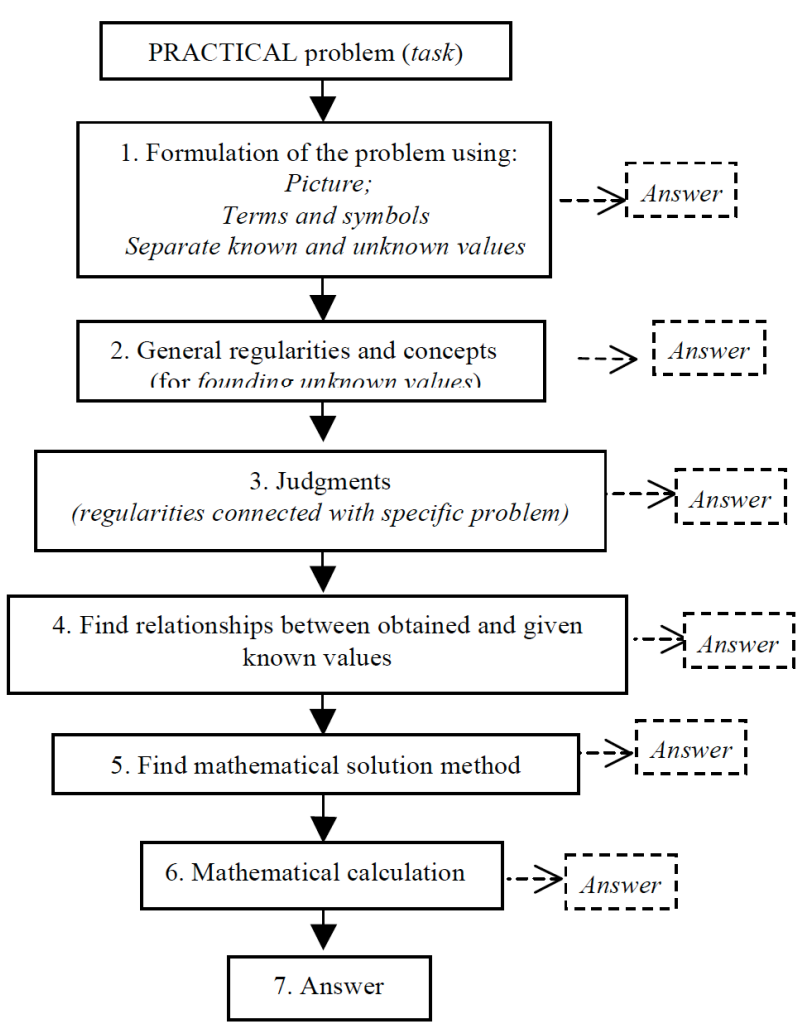

Figure 5. Frameworks for organization of practical problem solving in mathematics

\section{RESULTS AND DISCUSSION}

Based on a above mentioned didactical aspects of organization of practical problem solving in mathematics in e-environment and designed frameworks which consist of problem solving steps for self-directed studies and links consist the concepts and laws in mathematics and special subjects necessary for solution problem, was created the problem-solving examples and placed in the eenvironment. To determine students' perceptions on practical problem solving in mathematics in e-environment, the questionnaire was designed. More than 300 students from the specialties of Civil Engineering, Agricultural Engineering, Agricultural Power Engineering, Computer control and computer science and Programming at the Latvia University of Agriculture participated in the survey. 
Taking into account that the use of this activity, which contains the applicability of mathematics, students were not obligatory, at first it was necessary to determine students' interest in solving engineering problems, applying knowledge of mathematics "Fig. 6.".

The results show that $16.5 \%$ of students had no interest in the application of mathematics in solving engineering problems $-5.1 \%$ of students didn't open this activity and $11.4 \%$ of students opened this activity but didn't get the answers. This indicates the students' low level of motivation to study not only mathematics but also engineering. This explains the high student dropout in engineering specialty.

So if $83.5 \%$ of students had opened the activity and using offered problem solving steps, got the answers, then it was necessary to know the proportion of students who solved the problem independently using some links, who solved the problem independently using links and some answers and who only looked up the solution process using all the links and answers "Fig. 7.".

Disappointing is the fact that that $61.8 \%$ of students only checked the solution process. This shows not only the lack of students' interest, but also the students' low ability to solve problems independently.

The survey showed that $16.5 \%$ of students were not interested in offered practical problem solving in mathematics because they didn't open this activity or opened this activity, but did not get the answer. So it was interesting to find out the reason for not looking at these examples "Fig. $8 . "$

$2.4 \%$ of students openly admitted that they had no interest in the application of mathematics. $4.9 \%$ of the students said that they were not interested, as it was considered that there is a little sense in additional learning of another concepts and laws, taught in later courses. $9.2 \%$ of students reported that they would be willing to learn math applications, and even they would try to solve the problems independently, but they did not have the time. One

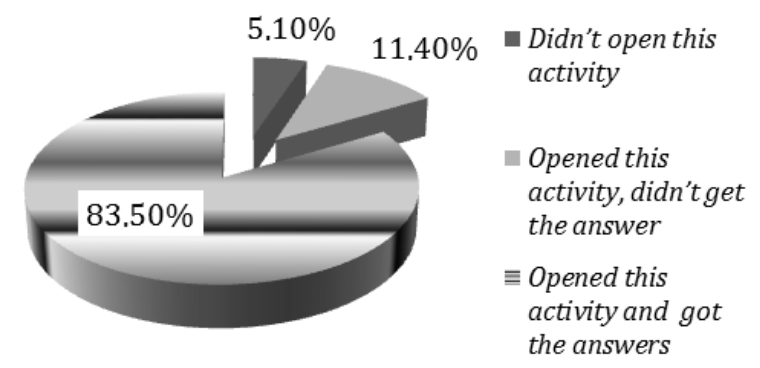

Figure 6. Students' interest in the applicability of mathematics

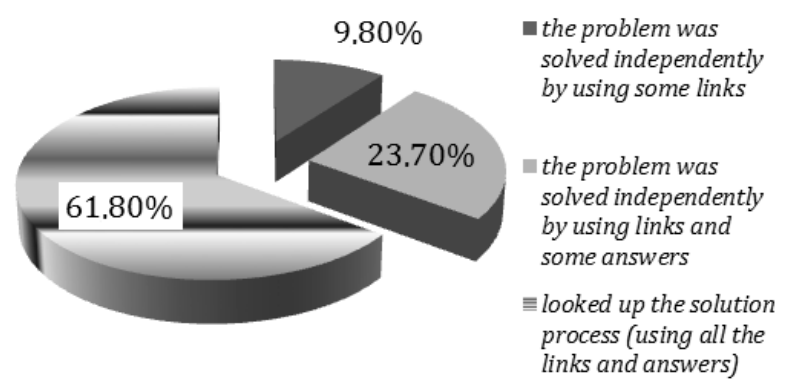

Figure 7. Proportion of self-directed studies in e- environment
ECTS in mathematics contains a relatively large amount of knowledge, besides the new knowledge is based on prior knowledge. If a student has a lack of the basic knowledge, then acquisition of higher mathematics require a lot of time and really there is not enough time to learn anything additional.

The fact that there is a correlation between students' success in mathematics and an interest in practical problem solving in mathematics is supported by the comparison of survey results with average success in mathematics of students from different specialties in the previous semester Table 1.

Figure 6 shows that average of $83.5 \%$ of students had opened the activity with practical problem solving in mathematics and using offered problem solving steps, got the answers. Table 1 shows the distribution of these results in separate engineering specialties at the Latvian University of Agriculture. The greatest interest has been shown by students from IT Programmer specialty, which can be explained by the relative better success in mathematics in the previous semester.

Similar correlation is also evident among the students of the specialties of agricultural power engineering, civil engineering and agricultural engineering. Students from specialty of computer control and computer science have shown the least interest in the application of mathematics, as most of these students still don't see relationships between the chosen specialty and need to solve different problems using higher mathematics. These students are also relatively weak in mathematics (average success in mathematics in the previous semester is only 5.1). Therefore, it seems that many students do not really understand that computer specialists are engineers, not residents of social networks.

\begin{tabular}{|c|c|c|}
\hline & & $9.20 \%$ \\
\hline & $4.90 \%$ & \\
\hline $2.40 \%$ & & \\
\hline $\begin{array}{l}\text { not interested at } \\
\text { all }\end{array}$ & $\begin{array}{l}\text { interested a } \\
\text { he moment }\end{array}$ & $\begin{array}{l}\text { interested, but I } \\
\text { didn't have time }\end{array}$ \\
\hline Figure 8. Rea & ns for not openi & this activity \\
\hline $\begin{array}{l}\text { COMPARISON OF INTERI } \\
\text { MATHEMATICS AND AVE }\end{array}$ & $\begin{array}{l}\text { ABLE I. } \\
\text { ET IN PRACTICA } \\
\text { AGE SUCCESS IN } \\
\text { VIOUS SEMESTE }\end{array}$ & $\begin{array}{l}\text { PROBLEM SOLVING IN } \\
\text { MATHERMATICS IN THE }\end{array}$ \\
\hline Specialty & $\begin{array}{l}\text { Opened this } \\
\text { activity and } \\
\text { got answers }\end{array}$ & $\begin{array}{l}\text { Average success in } \\
\text { mathematics in the } \\
\text { previous semester } \\
\text { (max 10) }\end{array}$ \\
\hline rogramming & $88.7 \%$ & 6.6 \\
\hline $\begin{array}{l}\text { Agricultural Power Engi- } \\
\text { eering }\end{array}$ & $87.9 \%$ & 6.2 \\
\hline Civil Engineering & $83.3 \%$ & 5.8 \\
\hline gricultural Engineering & $80.6 \%$ & 5.5 \\
\hline $\begin{array}{l}\text { Lomputer control and } \\
\text { omputer science }\end{array}$ & $76.9 \%$ & 5.1 \\
\hline
\end{tabular}




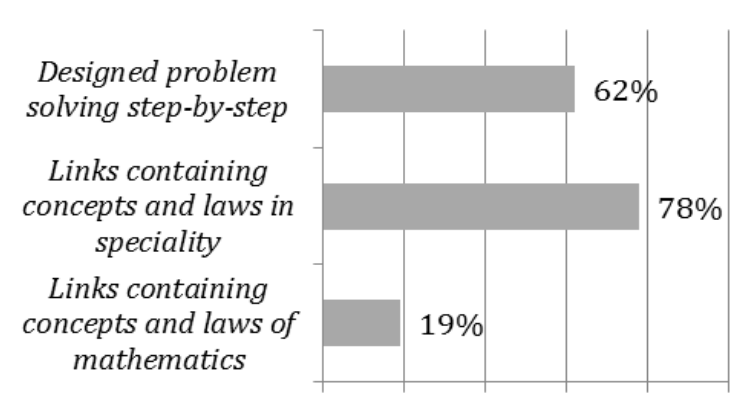

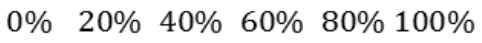

Figure 9. Importance of Frameworks of Practical Problem Solving in Mathematics

To determine the importance of designed frameworks of practical problem solving in mathematics the second questionnaire contained questions about importance of designed problem solving steps for self-directed studies as well as importance of offered links containing concepts and laws of special subjects and mathematics "Fig. 9.".

The results of this survey also show a low level of student ability to solve problems $(62 \%)$. The survey results show that $78 \%$ of students were required additional expertise on specific concepts and laws. So the question remains questionable for teaching mathematics usability, since mathematics is included in the $1^{\text {st }}$ and $2^{\text {nd }}$ year of the curriculum and students know little about their specialty. Technical concepts, offered in the links, are taken out of context and therefore they are not well understood by students.

The fact that $19 \%$ of students need links also in mathematics shows that students have little ability to apply learned mathematics topics in the specific situation.

\section{CONCLUSIONS}

Based on didactical aspects of organization of practical problem solving in mathematics in e-environment and designed frameworks which contain problem solving steps for self-directed studies and links consisting of the concepts and laws in mathematics and special subjects necessary for solution problem, the problem-solving examples were created and placed in the e-environment.

To determine students' perceptions on practical problem solving in mathematics in e-environment, the questionnaire was designed. The results show that $16.5 \%$ of students had no interest in the application of mathematics in the solving engineering problems. This indicates the students' low level of motivation to study not only mathematics but also engineering. On the other hand, many students lack basic knowledge in mathematics, therefore they consume a lot of time learning the basics in higher mathematics and acquiring the skills of practical problem solving in mathematics are less important.

The survey results show that $83.5 \%$ of students had opened the activity and using offered problem solving steps, got the answers, but only $9.8 \%$ of students solved the problem independently using some of links.

To solve the problems, more than $62 \%$ of the students had to use the designed framework which consists of the problem solving steps for self-directed studies. The survey results show that $78 \%$ of students were required additional expertise on specific concepts and laws. Technical concepts, offered in the links, are taken out of context and therefore they are not well understood by students.

Therefore, the main tasks of teaching mathematics are the matter of debate. Mathematics should be learned as a tool for solving different problems and specific problem areas should be left to the specialists. Application of mathematics should have only an illustrative aim for most students, but for "smarter" students designed examples in practical problem solving in mathematics in Eenvironment should have cognitive and developing aims.

\section{REFERENCES}

[1] OECD "Assessment Framework - Key competencies in reading, mathematics and science", PISA 2009, www.oecd.org/dataoecd/ 11/40/44455820.pdf

[2] M. Niss, " Curriculum, assessment, teacher training, skills ", The Danish KOM project and possible consequences for teacher education, Journal of research and training in mathematics education No 9:, Costa Rica, 2011 pp 13-24,.

[3] Mathematics in Europe: Common challenges and national policies. Brussels: Education, Audiovisual and Culture Executive Agency. Eurydice, 2011. Retrieved from http://eacea.ec.europa.eu/ education/eurydice/documents/thematic_reports/132EN.pdf [12]

[4] N. Taylor-Buckner "The Bologna Effect," Journal of Mathematics Education at Teachers College. Fall-Winter 2010, vol. 1, pp 42-45.

[5] A Framework for Mathematics Curricula in Engineering Education. SEFI Mathematics Working Group, 2011. http://sefi.htwaalen.de/Curriculum/Competency $\% 20$ based $\% 20$ curriculum_discu ssion document_December 2011.pdf

[6] S. Balciunas, R. Macaitiene, Virgailete-Meckauskaite, A. Vintere, A. Zeidmane, N.Paulins, "Development of Mathematical Competencies in Higher Education Institutions within Socio-Economical Context," Publishing House of Siauliai University, 2011, P.211. http://www.iipc.lv/saite1/petijums.html

[7] J.A.B. Lahins, T.A.M Ezis "Experience of Moodle Ale System Implementation and Comparison with Computerized Tests and other CMS Alternatives". Proceedings of the 4-Th International Scientific Conference,2010, pp.188-192.

[8] Glossary auto-linking filter. Moodle docs web page, Available at: http://docs.moodle.org/20/en/Glossary_auto-linking_filter [Accessed December 28, 2011].

[9] Lesson module. Moodle docs web page, Available at: http://docs.moodle.org/22/en/Lesson module [Accessed December 28, 2011].

[10] S. Mencke, R. Dumke, "A Hierarchy of Ontologies for DidacticsEnhanced E-learning," Proceedings of the ICL conference "ePortfolio and Quality in e-learning",Villach, Austria (CD), 2007

\section{AUTHORS}

A. Zeidmane is the Head of the Department of Mathematics, Latvia University of Agriculture, Latvia (e-mail: anda.zeidmane@1lu.lv)

V. Duka is with the Department of Mathematics, Latvia University of Agriculture, Latvia (e-mail: vita.duka@1lu.lv)

This article is an extended and modified version of a paper presented at the 16th International Conference on Interactive Collaborative Learning (ICL2013) and 42nd IGIP International Conference on Engineering Pedagogy, held from 25 to 27 September 2013 at Kazan National Research Technological University, in Kazan, Russia. Submitted 01 December 2013. Published as re-submitted by the authors 17 March 2014. 